\title{
Exploring the curing condition and age effect on thermal conductivity of concrete
}

\author{
Raychel Bahnick ${ }^{1 \S}$, Mohammad Joshaghani ${ }^{1}$, Omid Ghasemi-Fare, Ph.D..$^{{ }^{*}}$, and Zhihui Sun, Ph.D. ${ }^{1}$ \\ ${ }^{1}$ Department of Civil and Environmental Engineering, University of Louisville, USA
}

\begin{abstract}
Energy piles are used around the world to partially heat/cool buildings or de-ice pavements. Thermal conductivity of concrete is one of the key parameters which highly affects the thermal performance of energy geostructures. Application of higher thermally conductive concrete in energy piles helps to harvest more shallow geothermal energy. Besides, higher thermally conductive concrete results in more uniform temperature distribution and will significantly increase the efficiency of the geothermal bridge deck de-icing. It is expected that the thermal conductivity of the concrete depends on its age and the applied curing conditions. The thermal conductivity of concrete can progress with the progression of hydration. While the hydration process is highly dependent on the curing condition that is applied. In this study, several concrete samples are prepared and cured under different conditions (inside the humidity room, indoor, and outdoor). Then the thermal conductivity of concrete samples at different ages are measured according to ASTM D5470-17. Results show an increase in thermal conductivity of concrete cured in humidity room for the first 30 to 40 days that thermal conductivity were measured In addition comparison of thermal conductivity of the outdoor and indoor samples show the importance of the ambient temperature and relative humidity on the thermal conductivity value.
\end{abstract}

\section{Introduction}

Thermal conductivity of concrete is an important parameter in energy pile design. Higher thermal conductive concrete helps to harvest more geothermal energy through geothermal piles and increases the efficiency of the geothermal bridge deck de-icing. Thermal conductivity (k) of concrete is greatly affected by mix proportions, aggregate types, sources and sizes, moisture content and unit weight [1-3]. In addition, thermal conductivity of concrete can be influenced by the pore distribution and entrained air volume in the mix design. Pore distribution analysis using $\mathrm{x}$-ray tomography demonstrated that, air entrainment can be used as a sealer for thermal insulation [4]. It was also shown that in the wet state, the $\mathrm{k}$ value is higher due to the exceedance of air entrainer that leads to coalescing of bubbles. However, higher air volume reduces the density and negatively affects mechanical performance [4]. A separate study was conducted to determine how $\mathrm{k}$ value changes with variables such as admixture type and content (like fly ash and slag), coarse and fine aggregate type and content, age, temperature, water-to-cement ratio, and humidity condition, etc. It was found that age has minimal effect on thermal conductivity after 2 days while the volume of aggregate and the moisture condition of concrete have the greatest influences on the $\mathrm{k}$ value [5]. Concrete in the saturated condition is found to have a higher $\mathrm{k}$ value than concrete in the dry condition. It was also found that temperature and $\mathrm{k}$ value are indirectly proportional; as temperature increases, $\mathrm{k}$ value decreases [6]. This paper presents an experimental study carried out to measure the thermal conductivity of concrete. The study aims to understand how curing conditions and age affect concrete thermal conductivity.

\section{Experimental Setup}

The testing method considered in this study followed the ASTM D5470-17 [7]. The hot/cold plate used was a Teca Corp AHP-1200CAS Versatile Cascaded Cold/Hot Plate, the meter bars were Borosilicate Glass with a known thermal conductivity of $1.12 \mathrm{~W} / \mathrm{mK}$. The temperatures were recorded with a DATAQ Instruments Data Recorder Model DI-245 and the samples were insulated with high density insulation foam to reduce the radial heat loss produced in a 1D

\footnotetext{
* Corresponding author: Omid.ghasemifare@louisville.edu
} 
heat transport model.

Fig. 1 shows the lab setup. Two mix designs were considered in this study. For each mix design, nine identical samples were prepared. The specimens were cylinders with a height of $76.2 \mathrm{~mm}$ ( 3 inches) and a diameter of $101.6 \mathrm{~mm}$ ( 4 inches). In order to study the effects of the curing conditions, the concrete samples were kept and cured under three different conditions (humidity room, indoor and outdoor). Table 1 presents the summary of each curing condition. Three samples from the same batch were cured under the same condition to check the repeatability of the tests. All samples were demolded 24 hours after casting and then were kept at different conditions: humidity room (group A), indoor (Group B) and outdoor (Group C). Thermal conductivity of these samples were measured at different ages (from 4 days to 40 days). To measure the thermal conductivity of the samples, samples were placed on Cold/Heat plate while temperature of the Cold/Heat plate was fixed, and then the temperature of the both faces of the specimens as well the meter bars

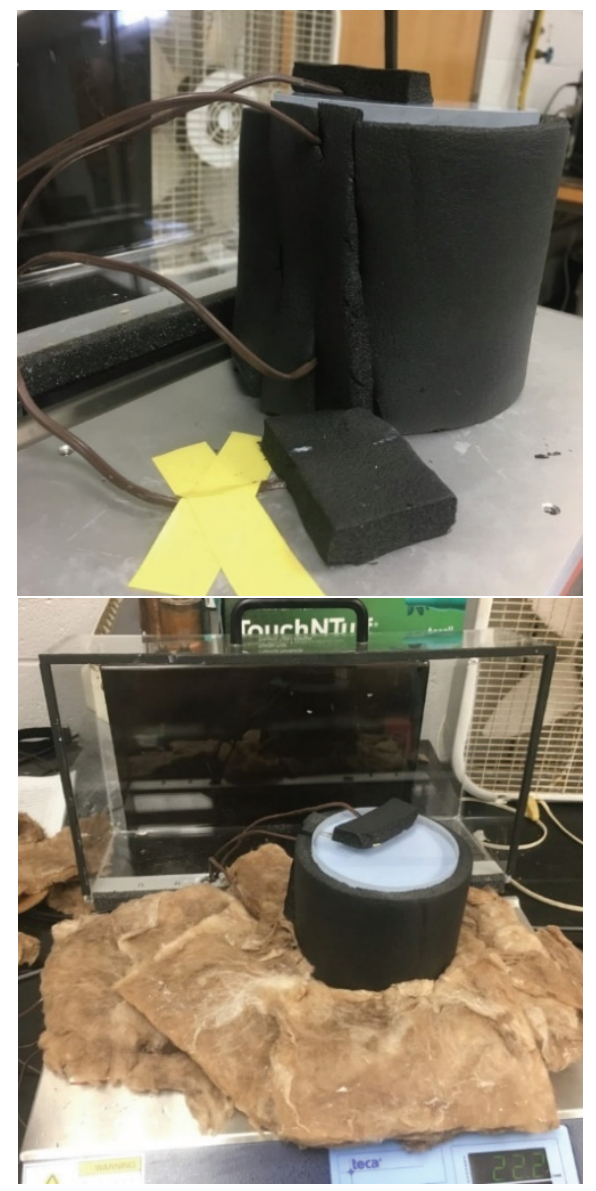

Fig. 1. Experimental setup including concrete sample, thermocouples, and Heat/cold plate were measured through the tests. Temperature was measured every 4.3 seconds for 10 hours and the thermal conductivity at the steady state condition was calculated. During the 10-hour test hot/cold plate was set to -30 degrees Celsius while the top meter bar was exposed to room condition. Please note, the test duration was selected such that the measured temperatures reach to steady state conditions.

Table 1. Summary of Curing Conditions

\begin{tabular}{|c|c|c|c|}
\hline & $\mathbf{A}$ & $\mathbf{B}$ & $\mathbf{C}$ \\
\hline $\begin{array}{c}\text { Curing } \\
\text { condition }\end{array}$ & $\begin{array}{c}\text { Humidity } \\
\text { Room }\end{array}$ & $\begin{array}{c}\text { Indoor } \\
\text { Conditions }\end{array}$ & $\begin{array}{c}\text { Outdoor } \\
\text { Conditions }\end{array}$ \\
\hline Samples & $1,2,3$ & $1,2,3$ & $1,2,3$ \\
\hline $\begin{array}{c}\text { Average } \\
\text { Humidity (\%) }\end{array}$ & 100 & 50 & 60 \\
\hline $\begin{array}{c}\text { Average } \\
\text { Temperature } \\
\left({ }^{\circ} \mathbf{C}\right)\end{array}$ & 22.2 & 22.2 & $16.7-26.7$ \\
\hline
\end{tabular}

\subsection{Materials and Sample Mix}

Mix 1 and Mix 2 had similar mix designs except the amount of air entrainer. Type I/II Portland cement and river sand (as fine aggregate) were used in both mix designs. The coarse aggregates in the both mixes were \#57 limestone. Table 2 presents the mix designs for both cases. The air entrainer was added to Mix 2 to observe the effects of air volumes on thermal conductivity of the concrete. Air entrainer introduces uniform micro air voids throughout the concrete which can be filled with water when concrete is saturated. In case of high air volume in concrete, the thermal conductivity can dramatically change for dry and saturated condition. Therefore, the effect of environmental condition for the samples with high amount of air contents should be studied [5].

Table 2: Mix 1 and 2 Designs

\begin{tabular}{|c|c|c|}
\hline & Mix 1 & Mix 2 \\
\hline Cement (kg) & 5.84 & 5.84 \\
\hline Fly ash (kg) & 1.46 & 1.46 \\
\hline Water (kg) & 3.05 & 3.05 \\
\hline Fine aggregate (kg) & 13.97 & 13.97 \\
\hline Coarse aggregate (kg) & 21.59 & 21.59 \\
\hline Air entrainer (ml) & - & 47.61 \\
\hline Superplasticizer (ml) & 36.97 & 36.97 \\
\hline
\end{tabular}




\section{Experimental Results}

While it has been found in literature that age has limited effect on the thermal conductivity of concrete [5], the results showed hydration process in the first 28 days might affect the thermal conductivity value especially for samples placed inside the humidity room. Fig. 2 presents the variation of thermal conductivity for different curing conditions. Experimental measurement shows that thermal conductivity can significantly increases if the hydration process is more advanced. Variations of the thermal conductivity of samples placed outdoor highly depends on the relative humidity and ambient temperature which controls the evaporation from the samples. Please note, thermal conductivity of the samples could not be measured at the same day since thermal conductivity test for each test could take up to 10 to 15 hours in order to make sure temperature at the top and bottom of the concrete samples reach to the steady state condition.

Fig. 3 demonstrates the variation of concrete thermal conductivity cured at the indoor condition. Results obtained from both mix designs are almost identical. At the age of 10 days thermal conductivity measured for samples from Mix 1-Group B was equal to $0.87 \mathrm{~W} / \mathrm{mK}$ which is very close to the thermal conductivity of samples from Mix 2 under same curing condition $(0.88 \mathrm{~W} / \mathrm{mK})$. However if air contents increases more drastically the thermal conductivity, density, and strength will be reduced if air bubbles get connected [5].

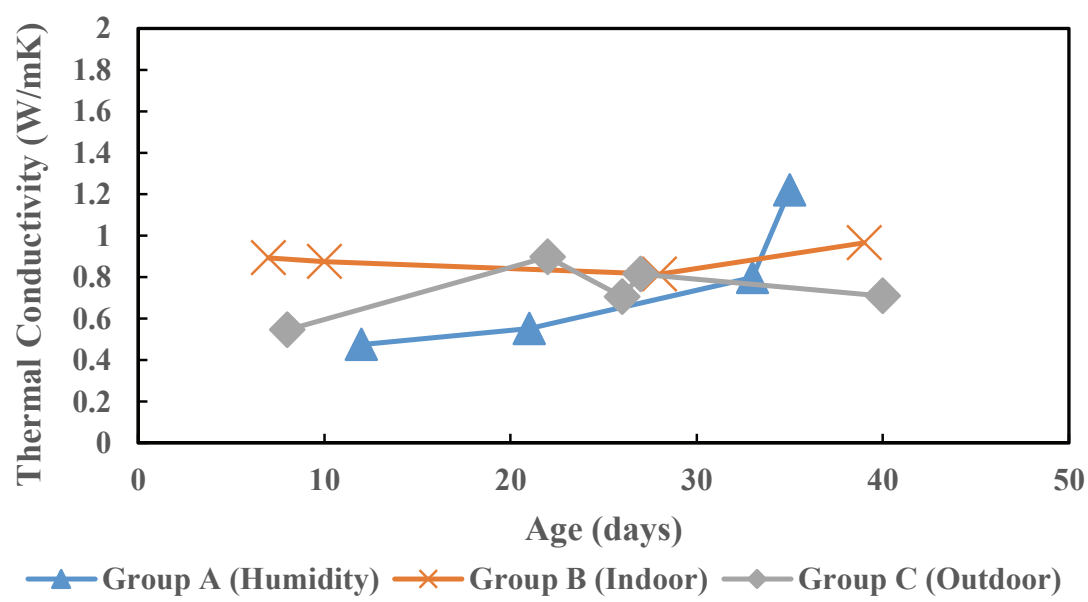

(a)

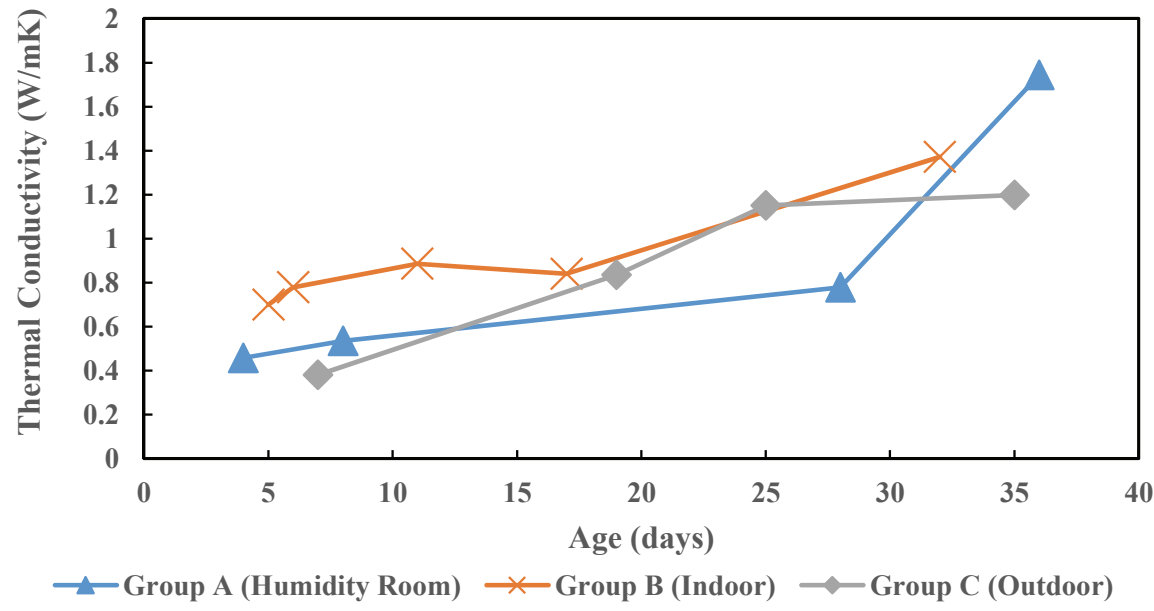

(b)

Fig. 2. Variation of thermal conductivity of concrete samples: (a) Mix 1, (b) Mix 2

Fig. 4 compares the variations of the thermal conductivity at different ages for both Mix 1 and 2 
cured in the humidity room. In the early age of the concrete, Mix 1 and Mix 2 showed similar thermal conductivity values. However, the thermal conductivity of samples from Mix 2 were slightly higher than that of Mix 1. As mentioned before air entrainer was used in Mix 2 and the air pores were filed with water while it was placed in the humidity room. Fig. 5 shows the variations of thermal conductivity of concrete samples placed outdoor. Comparing Fig. 5 to Figs. 3 and 4, it is confirmed that the thermal conductivity of Group $\mathrm{C}$ samples for both Mix 1 and Mix 2 show higher variations compared to all other samples. Since all these samples were cured outdoor and were exposed to ambient condition; changes in temperature, relative humidity and precipitation at different days for Mix 1 and Mix 2 result in different thermal conductivity values. The first test for Mix 1 was conducted on a hot, dry day during summer with the average daily temperature being $29.3{ }^{\circ} \mathrm{C}$ and no precipitation, the result was the lowest recorded thermal conductivity. The following three tests decreased and increased sharply, and these test days observed up to 1.78 centimeters of rainfall and average daily temperatures ranging between 10 and 15.6 degrees Celsius. The final test taken at the age of day 40 concluded with a decrease in thermal conductivity on a dry day with no precipitation recorded [10].

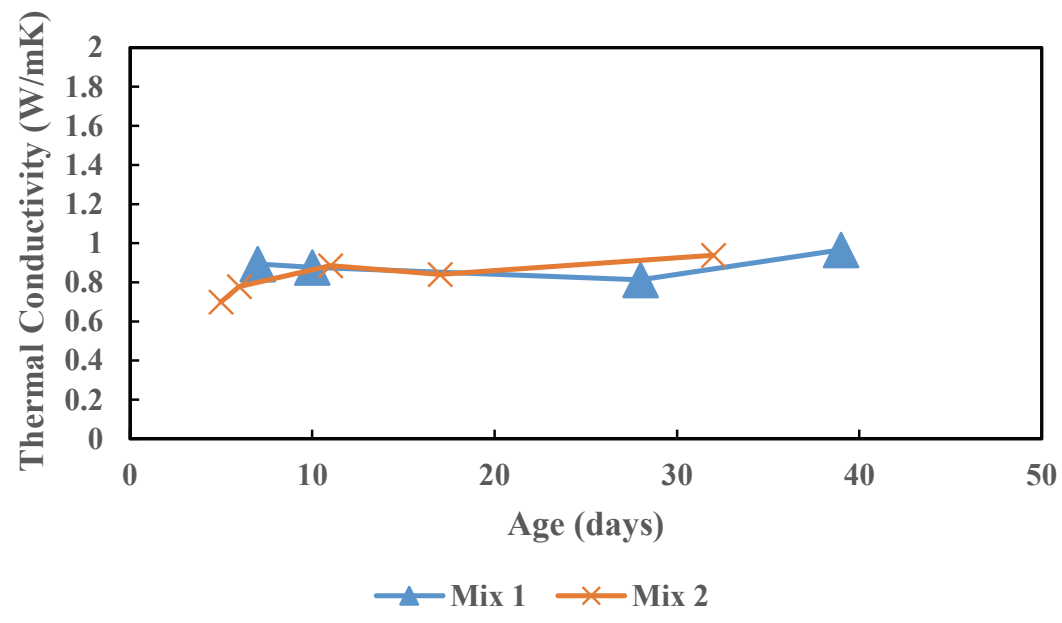

Fig. 3: Group B (Indoor condition) results comparison for Mix 1 and Mix 2

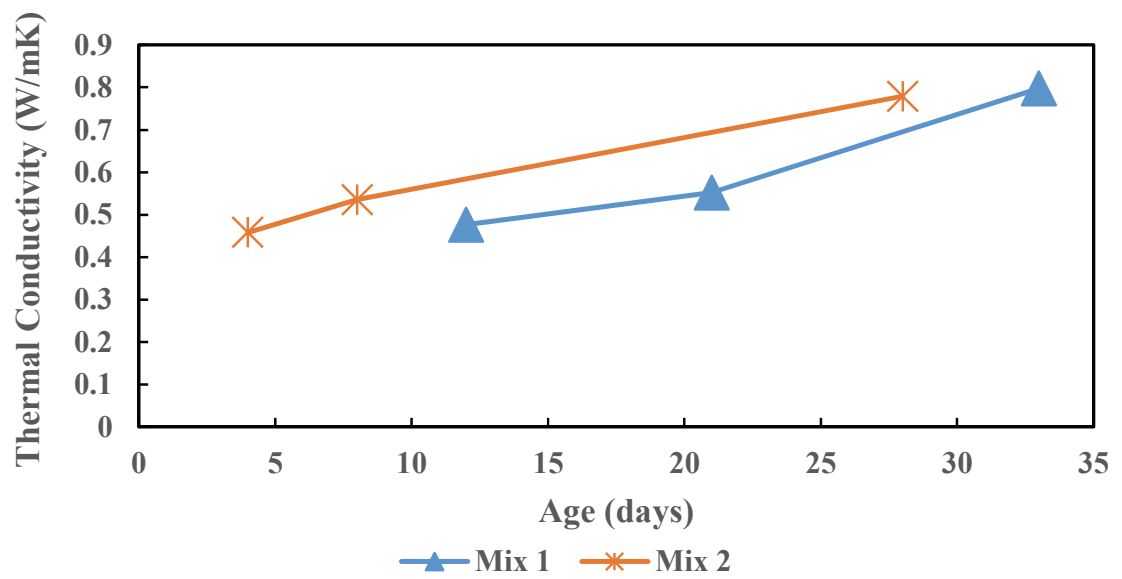

Fig 4: Group A (Humidity Room) results comparison for Mix 1 and Mix 2 
Tables 3, and 4 presents the average ambient temperature and precipitation for Mix 1 and Mix 2, respectively. The second series of thermal conductivity tests on Group C samples from Mix 2 were performed during the winter which had lower temperature and higher precipitation. Lower evaporation and higher relative humidity of ambient condition during the winter results in increasing thermal conductivity for Mix 2 .

\section{Summary}

This study explored how thermal conductivity of concrete can be influenced by curing conditions and age. It is known that properties of concrete are affected by volume ratio of its mix design, such as voids, cement, and aggregate. The voids inside concrete and the quantity and characteristics of them have an important effect on the mechanical and thermal properties of concrete [11]. However, it has been observed that thermal conductivity of concrete cured inside the humidity room increases with age until the hydration completes. The environmental conditions such as humidity and temperature also change the thermal conductivity of concrete. Samples cured outside showed higher variations; those were tested in hot summer days had less thermal conductivity value while those were tested under low temperature and high precipitation conditions showed higher thermal conductivity. Future research is needed to further examine with additional test results of other variables such as size of aggregates, higher water contents, and many other factors on different types of concrete.

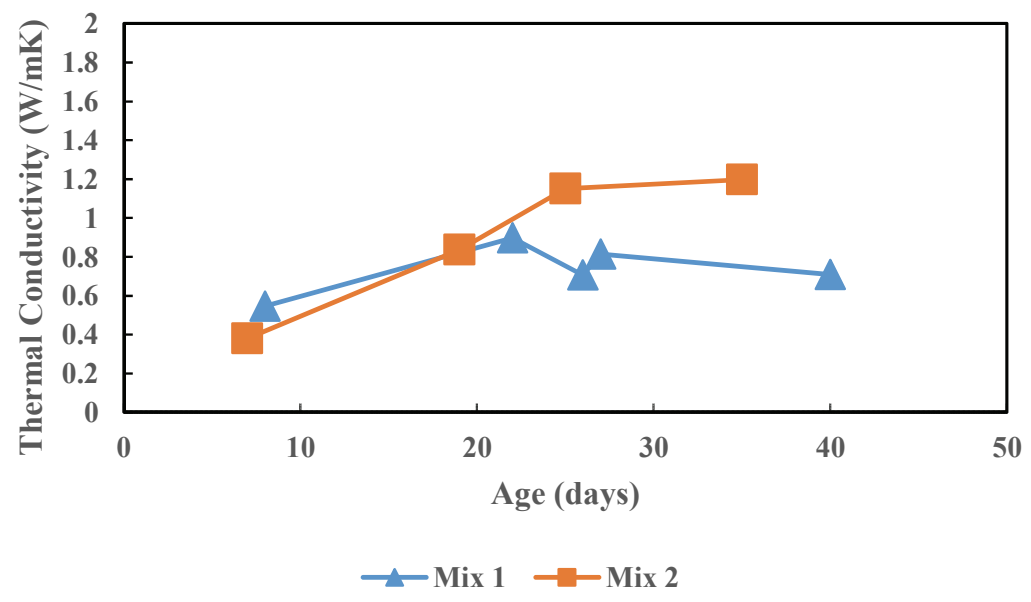

Fig 5: Group C (Outdoor Climate) results comparison for Mix 1 and Mix 2

Table 3: Summary of the weather conditions during Mix 1 Group $C$ test

\begin{tabular}{|c|c|c|c|}
\hline Age & Date & Ave. Temperature (C) & Precipitation (cm) \\
\hline 8 & $28-$ Sep & 29.3 & 0 \\
\hline 22 & 11 -Oct & 16.9 & 0 \\
\hline 26 & $15-$ Oct & 17.2 & 0 \\
\hline 27 & $16-$ Oct & 12.3 & 1.78 \\
\hline 40 & $29-$ Oct & 14.3 & 0 \\
\hline
\end{tabular}

Table 4: Summary of the weather conditions during Mix 2 Group $C$ test

\begin{tabular}{|c|c|c|c|}
\hline Age & Date & Ave. Temperature (C) & Precipitation (cm) \\
\hline 7 & 21-Nov & 11.1 & 0 \\
\hline 19 & 3-Dec & 3.3 & 0.1 \\
\hline 25 & $9-\mathrm{Dec}$ & 14.6 & 0.22 \\
\hline 35 & 19-Dec & -0.4 & 0.25 \\
\hline
\end{tabular}


The authors gratefully acknowledge the financial support by the Kentucky Transportation Cabinet. Authors would also like to thank Mr. Jon Wilcoxon, Assistant State Highway Engineer, Jarrod Stanley, Research Coordinator, and Wesley Glass from Materials Division at KYTC.

\section{References}

[1] P. Morabito, Measurement of the thermal properties of different concretes, High Temp. High Press. 21 (1989) 51-59.

[2] A.M. Nevile, Properties of Concrete, Longman, UK, 1995.

[3] A. Lanciani, P. Morabito, P. Rossi, Measurement of the thermophysical properties of structural materials in laboratory and in site: methods and instrumentation, High Temp. High Press. 21 (1989) 391-400.

[4] Peruzzi, A. P., Rossignolo, J. A., \& Kahn, H. (2018). Air-entrained Concrete: Relationship between Thermal Conductivity and Pore Distribution Analyzed by X-Ray Tomography. Journal of Civil Engineering and Architecture, 12(7). doi: 10.17265/19347359/2018.07.005

[5] Kim, K.-H., Jeon, S.-E., Kim, J.-K., \& Yang, S. (2003). An experimental study on thermal conductivity of concrete. Cement and Concrete Research, 33(3), 363-371. doi: 10.1016/s00088846(02)00965-1

[6] Asadi, I., Shafigh, P., Hassan, Z. F. B. A., \& Mahyuddin, N. B. (2018). Thermal conductivity of concrete - A review. Journal of Building Engineering, 20, 81-93. doi: 10.1016/j.jobe.2018.07.002

[7] Test Method for Thermal Transmission Properties of Thermally Conductive Electrical Insulation Materials. (n.d.). doi: 10.1520/d5470

[8] Narayanan, N., and Ramamurthy, K. 2000. "Structure and Properties of Aerated Concrete: A Review." Cement \& Concrete Composites 22: 321-9.

[9] Nevile, A. M. 2016. Propriedades do concreto. Porto Alegre, Brazil: Bookman

[10] Louisville, KY Weather History star rate home. (n.d.). Retrieved January 30, 2020, from https://www.wunderground.com/history/weekly/ us/ky/louisville/KSDF/date/2019-10-29

[11] S.-Y. Chung, T.-S. Han, S.-Y. Kim, J.-H.J. Kim, K.S. Youm, J.-H. Lim, Evaluation of effect of glass beads on thermal conductivity of insulating concrete using micro CT images and probability functions, Cem. Concr. Compos. 65 (2016) 150-162. 